\title{
La primera infancia indigena: entre la escolarización y la familia
}

Indigenous First Childhood: Between Schooling and Family

A Primeira Infância Indígena: entre Escola e Família

Martha Janeth Ibáñez-Pacheco* iD orcid.org/0000-0002-0953-3917

Para citar este artículo: Ibáñez-Pacheco, M. (2021). La primera infancia indígena: entre la escolarización y la familia. Revista Colombiana de Educación, /(81), 357-372. https://doi.org/10.17227/rce.num81-10827

\section{(c) $(1) \Theta$}




\section{Resumen}

Si bien la lucha ganada por las comunidades étnicas dio como resultado en el siglo xx, el proyecto etnoeducativo en la Ley general de educación, su puesta en marcha se ha constituido en todo un desafio, no solo para las comunidades mismas, sino para las universidades que forman a los profesores y profesoras. En medio de desencuentros, este trabajo muestra una práctica pedagógica, que se volvió investigativa porque se reestructuró a sí misma para situarse como una pedagogía insurgente y enrumbarnos hacia la etnografía educativa como metodología que permitió reconocer formas de ser y vivir para y con el territorio de las comunidades indígenas Achagua y Piapoco del resguardo La Victoria-Umapo, en Puerto López (Meta, Colombia), quienes nos permitieron desaprender nuestras propias prácticas pedagógicas "colonizadoras". El artículo da cuenta del proceso investigativo de la práctica pedagógica con las familias y los niños de la primera infancia que asisten a la escuela rural multigrado ubicada en el centro del resguardo y cuyos maestros fueron formados en la universidad, desde estructuras occidentalizadas. Por esta razón, la escuela parece detenida en el tiempo. Sus prácticas y organización responden, desde su imaginario, a demandas de un régimen occidental educativo que les garantiza el aprendizaje del español y lo básico para vincularse al sistema económico y social de la región. Así, los niños y niñas indígenas y blancos de la primera infancia que van a la escuela son sujetos de aprendizaje occidental.

\section{Palabras clave}

primera infancia; comunidades indígenas; relaciones escuelafamilia; etnicidad- educación; educadores; cosmovisión

\section{Keywords}

early childhood; indigenous

populations; school-family relationship; ethnicityeducation; educators; worldview

\begin{abstract}
Although the ethnic communities' struggle turned out, in the twentieth century, in the ethnical and educational project in the General law on education, its implementation has been a challenge, for the communities themselves and for teacher-training universities alike. This work shows a pedagogical practice that became investigative because it re-structured itself to become an insurgent pedagogy. It also led us to educational ethnography as a methodology which helped us recognize ways of being and living for and with the territory of the Achagua and Piapoco indigenous communities from La Victoria-Umapo resguardo, in Puerto López (Meta, Colombia), who allowed us to unlearn our own pedagogical "colonizing" practices. The article gives an account of the research process of the pedagogical practice with first childhood children who attend the multi-grade rural school located in the middle of the resguardo, and whose teachers were trained at the university from westernized structures. Consequently, the school seems stopped in time. Its practices and organization respond-according to its own imaginaryto the demands of a Western educational regime that guarantees the community the learning of Spanish and the basic skills and knowledge to join the social and economic system of the region. Therefore, early childhood indigenous and white children who attend school are subjects of Western learning.
\end{abstract}

\section{Resumo}

Embora a luta vencida pelas comunidades étnicas resulte no século xx, do projeto etnoeducativo na Lei geral de educação, sua implementação tornou-se um desafio, não só para as próprias comunidades, mas para as universidades. que treinam professores. Em meio a desentendimentos, este trabalho mostra uma prática pedagógica, que se tornou investigativa porque se reestruturou para se posicionar como uma pedagogia insurgente e se voltou para a etnografia educacional como metodologia que nos permitiu reconhecer modos de ser e de viver para e com o território das comunidades indígenas Achagua e Piapoco da reserva La Victoria - Umapo, em Puerto López (Meta - Colômbia), que nos permitiram desaprender nossas próprias práticas pedagógicas "colonizadoras". O artigo relata o processo investigativo da prática pedagógica com famílias e crianças da primeira infância que frequentam a escola multisseriada rural localizada no centro do resguardo e cujos professores foram formados na universidade, a partir de estruturas ociden-

N. 81 talizadas. Portanto, a escola parece parada no tempo, as suas práticas e organização respondem, desde o seu imaginário, às exigências de um regime educativo ocidental que lhes garanta a aprendizagem do espanhol e as noções básicas ligadas ao sistema económico e social da região. Assim, as crianças indígenas e brancas na primeira infância que vão à escola são sujeitos da aprendizagem ocidental.

\section{Palavras-chave}

primeira infância; comunidades indígenas; relações escola - família; etnia - educação; educadores; visão de mundo 
Somos viento, nosotros. No el pecho que nos sopla. Somos palabra, nosotros. No los labios que nos hablan.

Somos paso, nosotros. No el pie que nos anda. Somos latido, nosotros. No el corazón que lo pulsa.

Somos puente, nosotros. No los suelos que se unen. Somos camino, nosotros. No el punto de llegada ni de partida. Somos lugar, nosotros. No quien lo ocupa. No existimos, nosotros. Sólo somos.

SUBCOMANDANTE MARCOS

\section{Introducción}

Mientras la sociedad se fragmenta y establece relaciones sociales distantes, temerosas, con niños enclaustrados y protegidos que responden a lo que Bustelo (2011) Ilama "[...] dispositivos relacionados con el bios" ${ }^{1}$, esto es, el control de los que sobreviven [refiriéndose a los excluidos], a través de la construcción de la legitimidad de una visión hegemónica de la infancia" (p. 35). Es una sociedad controladora que asume la protección y el cuidado desde el encerramiento físico y que crea subjetividades condicionadas en lo estético, ético y político, dependientes del control.

Pese a esta práctica "occidental", como la Ilaman las comunidades indígenas achagua y piapoco en el resguardo La Victoria-Umapo, en Puerto López (Meta, Colombia), perviven en su condición comunitaria, que se podría leer como acción emancipadora o de resistencia, si se quiere. Igualmente, buscan salvaguardar su cultura con la comunicación en su propia lengua (piapoco y achagua, perteneciente a la familia lingüística Arawak), la elaboración del casabe y el mañoco, ${ }^{2}$ la pesca, la preparación de las fiestas y la siembra, la familia extensa vecinal, los juegos tradicionales y propios, entre otros, que garantizan su condición cultural y social como pueblo ancestral, pese a procesos de aculturación manifiestos en sistemas educativos, organizativos, religiosos, políticos impuestos desde lógicas derivadas de una "epistemología occidental dominante" (Santos, 2010).

1 La cursiva es del autor, retoma el concepto griego, en el cual la zoé, se expresaba como la pureza de la vida y el bios, la vida relacional que implica: el lenguaje, la política y la ciudanía. Para el caso de la infancia, dice el autor, "la zoé es la sobrevivencia y el bios es la ciudadanía y la política" (p. 24).

2 Casabe o cazabe es un pan elaborado a base de harina de yuca brava procesada que se moja y se prepara como una gran arepa circular y se asa al fuego sobre una plancha de piedra. El mañoco es casabe en polvo que se agrega a las sopas o agua. Su preparación y consumo es de tiempos ancestrales y es propio de las comunidades indígenas; su elaboración está en manos de las mujeres y es un alimento diario que se consume con carnes, sopas, su sabor es un tanto agrio, pero gustoso al paladar. 
La comunidad indígena Achagua en los Llanos Orientales está ubicada en las sabanas del río Meta, Casanare y Ariporo, con asentamientos en los resguardos de la Victoria-Umapo y en el resguardo El Turpial en el municipio de Puerto López, departamento del Meta; compuesta por aproximadamente 559 indígenas y en el municipio de Paz de Ariporo (Casanare) por 117. En otras regiones del país también se encuentra dispersa la población Achagua, debido a las características de movilidad a las que se han visto forzados por circunstancias diversas, por lo que se considera que existen 796 indígenas que pertenecen a la familia lingüística Arawak (Arango y Sánchez, 2006, citado por Ardila, 2015).

A la llegada de los españoles, la comunidad Achagua era una de las más numerosas y se extendía hasta Venezuela. Hoy, su economía se basa en el cultivo de la yuca brava, el maíz, la caza y la pesca, lo mismo que en el trabajo asalariado en fincas aledañas, el cultivo de la coca y el trabajo en las fazendas,

[...] Liderado por la empresa Aliar s. A. que se inspiró en modelos agroindustriales de Brasil que utilizan grandes extensiones de tierra, para desarrollar su proyecto en los municipios de Puerto López y Puerto Gaitán (Meta), en 11 fincas, de las cuales 9 son en comodato. La planta de sacrificio ubicada en Puerto Gaitán, en la finca Barlovento, en un lote de 300 hectáreas con capacidad en espacio para 480 cerdos y una capacidad de sacrificio de 240 cerdos por hora y 1920 cerdos por día. (El Tiempo, 28 de mayo del 2015).

Si bien esta industria ha empleado a personas de la región, también ha cambiado las prácticas y costumbres del trabajo y de la estructuración social y territorial, este proceso no se hace en acuerdo con la comunidad sino que se les ofrece un arriendo muy exiguo por el uso de las tierras, con lo cual se disminuye el territorio para la siembra de sus propios productos y se ocasiona a corto plazo el deterioro ambiental por los olores que expide esta práctica, así como el uso inadecuado de la tierra y la utilización del agua en grandes cantidades. Existe, sin embargo, y a pesar de las pocas prácticas agrícolas, un intercambio comercial con la comunidad vecina Sikuani y otros grupos que se encuentran en la región.

El trabajo de las misiones evangelizadoras, colonizadoras y de expansión desde el siglo xVIII han afectado los procesos culturales, sociales y de organización dentro de las comunidades, como lo mencionan los historiadores, frente a usanzas como la caza, la pesca, la siembra de productos y prácticas culturales que han sido parte de su supervivencia. Como lo mencionan los profesores de la escuela rural Achagua José D. Gaitán y Luis Alonso Gaitán, nativos y profesores en ejercicio de la escuela multigrado del resguardo Piapoco-La Victoria: 
[...] las tradiciones culturales están en riesgo, y afectan la tradición (eway iwita) o especialista en artesanías o ciencias del artesano, en el resguardo Piapoco de la Victoria por efectos de la aculturización, el modernismo, territorio reducido, y la falta de motivación y voluntad ${ }^{3}$ en las nuevas generaciones en aprender la valiosísima tradición ancestral; como ciencia artesanal que tiene que ver con la fabricación de objetos para el uso de la vida cotidiana y los oficios de la tierra y de la recolección. Algunos de estos objetos son reemplazados por utensilios occidentales que son adquiridos con poco dinero. (Entrevista 5, informe de práctica 2018-II, 24 de octubre del 2018).

Otra práctica que pone en riesgo la tradición, dicen los profesores, es la constante reducción del territorio por la ocupación de las multinacionales en la explotación del petróleo y la explotación de la tierra por parte de la empresa privada que se apropia de grandes extensiones de tierra, que antes eran del resguardo. Este hecho, entre otros, hace que no se pueda sembrar la materia prima necesaria para la transmisión de las costumbres en la elaboración de los objetos de uso y con ello, como lo dice Walsh (2013), se atenta contra la posibilidad de construir una memoria colectiva, que se articula con una "apuesta decolonial", para romper los parámetros establecidos por el sistema educativo homogeneizante. Igualmente, la transmisión de la cultura en relación directa con el territorio ancestral, su conservación y la pervivencia de la educación propia. Dicen los mismos profesores que

[...] esta problemática vivencial los lleva a perder un valor ético y moral que milenariamente se venía transmitiendo. Con todo esto, esta tradición tan valiosa ha afectado las motivaciones, la voluntad de las nuevas generaciones en apreciar y aprender y a medida que los jóvenes no quieren aprender o no hay motivos, los sabedores le llega su término de vida y se van Ilevando todos esos conocimientos.(Entrevista 5, informe de práctica 2018-II, 24 de octubre del 2018).

Afirmaciones como las de los profesores Gaitán evidencian que los símbolos y significaciones inscritos en los objetos y las costumbres cobran valor ético-político cuando se reclaman como propios, por ello un hecho que parecería trivial, por ejemplo el uso de la vasija de plástico en lugar del totumo, rompe con una práctica que no solo conecta con el territorio, sino que fracciona las dinámicas propias de la consolidación comunitaria. Estas y otras conversaciones nos llevaron a preguntarnos si el concepto de etnoeducación ha trascendido las prácticas escolares en la primera infancia o si traslapó a una escuela positivista con alumnos y profesores, donde, como plantea Castillo: "[...] está en juego, en últimas, la capacidad de tramitar la plurietnicidad en una perspectiva amplia, y no de reducción y recorte de su naturaleza diversa, compleja y dispersa" (2008, p. 23). Esto

3 El énfasis lo ponen los mismos profesores cuando explican y describen el problema. 
en tensión con los procesos de descentralización que obligan además a responder a sistemas estandarizados que no se movieron para atender lo que demandaba la Constitución de 1991.

Para Semper (2006), los sectores indígenas del país materializaron la condición de ciudadanos y de sujetos de derechos en la Constitución Política expedida el 20 de julio de 1991, y además se crearon instrumentos jurídicos para su exigencia y defensa, como la acción de tutela y el reconocimiento institucional por parte de la Corte Constitucional, que “Desde que inició su labor a la fecha (2006), ha dictado más de cincuenta sentencias, sobre los derechos de los indígenas, las que intentan iluminar las dudas existentes en cuanto a disposiciones constitucionales" (p. 2).

Estas acciones jurídicas responden a la declaración constitucional de Colombia como país pluriétnico y multicultural y establecen el derecho de los grupos étnicos en sus territorios a la práctica de sus tradiciones lingüísticas propias; por ello, la Ley 115 de 1994, ley general de educación, reconoce en los grupos indígenas el derecho a respetar y desarrollar su identidad cultural. El Decreto 804 del 18 de mayo de 1995 reglamenta la educación étnica como parte del servicio público y declara como principios de la etnoeducación: Integralidad, diversidad lingüística, autonomía, participación comunitaria, interculturalidad, flexibilidad, progresividad y solidaridad.

Lo anterior se ha constituido en un marco de actuación en el ámbito educativo de algunas comunidades indígenas organizadas que han construido colectivamente su propio Proyecto Educativo Institucional, que transita desde su autodeterminación a Proyecto Educativo Comunitario, con una prevalencia en la preservación de la lengua materna, costumbres y prácticas ancestrales rescatadas por ellos mismos, y se dio con fuerza organizativa en algunas comunidades, como las del departamento del Cauca, de Risaralda e incluso de la capital, Bogotá. En las comunidades Achagua y Piapoco de Puerto Gaitán la preocupación central ha sido la construcción de la escuela con sus propios esfuerzos y el nombramiento de los profesores nativos, pero consideramos, como parte del análisis que nos dejó la práctica investigativa, que el proyecto pedagógico propio está por construirse y deconstruirse, puesto que las prácticas pedagógicas están encoradas en una tradición educativa derivada de lo que Castillo (2008) Ilama, Iglesia-docente. Algunas organizaciones indígenas ya han rechazado estas prácticas como formas de escolarización impuestas desde el siglo xVI, que son el significado de las misiones católicas en su papel civilizatorio que, además, han influenciado la estructura misma de las comunidades. Es lo que la autora ha llamado "la lucha por otra escuela".

Igualmente, Rojas (2019) afirma que hay prácticas que prevalecen a pesar de las legislaciones que favorecen a los pueblos y su autodeterminación. Estas, dice el autor, reflejan tensiones, especialmente en el plano educativo, en sus prácticas y concepciones, a pesar de que se haya hecho tránsito de 
la etnoeducación "[...] hacia la educación bilingüe, posteriormente a la educación bilingüe intercultural; Educación propia, y más recientemente, Sistema Educativo Indígena Propio (SEIP)" (p. 9), motivadas todas estas por la fuerza de los movimientos y las sentencias de la Corte Suprema.

Uno de los vacíos que había planteado el mismo Rojas (2019) frente a la educación intercultural, tanto en su legislación como en su puesta en práctica, es que haya sido definida con exclusividad para las comunidades afrocolombianas e indígenas. Eso ya las hace excluyentes puesto que, por un lado, es una condición de diversidad cultural que atañe a todos los ciudadanos colombianos, no exclusivamente a estos dos grupos poblacionales. Otro vacío es que se refiere a la diversidad y la diferencia solo con relación a sus sistemas culturales, con una displicencia homogeneizante puesto que no está en relación con el territorio, que es lo que da el carácter real de ancestralidad, porque los sistemas construidos se dan con respecto a este, no solo en el plano ambiguo del "reconocimiento de la diversidad".

En esta lectura etnoeducativa que hace el Ministerio de Educación Nacional y en un afán por atender una población que constituye el cumplimiento de la Ley 115, hace algunos esfuerzos por difundir, divulgar y poner en el plano público una educación situada, lanza programas en convenio con entidades privadas que atienden a esta especificidad, por ejemplo, el proyecto SAl, ${ }^{4}$ Con guías de aprendizaje que sitúan el contexto y la cultura en su centro y dan elementos para que tanto las mismas comunidades como los blancos o los no pertenecientes a las comunidades puedan comprender el marco de la diversidad en rituales, cocina, sabedores, mitos, leyendas ancestrales, trabajo y artesanías. Es un material que está construido desde la concepción de guías educativas, como las de la escuela rural. Está estructurado en tres niveles, donde cada uno contempla un actor específico de la comunidad, pero todo está en español, lo que implica que los actores comunitarios deben saber la segunda lengua, lo que no se ajusta a la realidad.

Por otro lado, el Instituto Colombiano de Bienestar Familiar, que depende del Departamento Administrativo para la Prosperidad Social (DPS) y cuyo foco de atención es la primera infancia, en el ejercicio de la política pública De Cero a Siempre (Ley 1804 del 2016), desarrolló entre el 2016 y el 2019 un programa de atención educativa y produjo una serie de materiales denominada Agua, viento y verdor", dirigida a cuidadores y educadores de la primera infancia indígena, pero no contempla a la escuela

4 Sabiduría Ancestral Indígena (2015), proyecto educativo intercultural desarrollado por el grupo empresarial suRA (Suramericana de Seguros Financieros) dedicado a los niños de las comunidades indígenas de Colombia con 24 guías de aprendizaje, narraciones, cuentos, mapas, relatos. http://www.memoriaycreatividad.com/home/sai/ acerca-de-sai/ 
indígena donde se encuentran los niños de transición que están entre los cuatro y seis años de edad, puesto que es un sistema de protección que no dialoga con el Sistema Educativo Colombiano del MEN, porque son niños escolarizados. Esto deja ver que es un sistema que corresponde a una concepción biologicista del desarrollo infantil y no a una condición etnoeducativa e intercultural de la infancia.

Estos esfuerzos de alguna manera son construidos por un Gobierno centralista y excluyente que tiene una concepción de la cultura indígena de accesorio y no como sistema vital, que está interconectado desde una concepción cosmogónica del territorio. Aun así, no llegan al total de las comunidades, por falta de información o porque la circulación de esta no forma parte de la cultura escolar educativa de las escuelas rurales de las comunidades indígenas o porque la formación de los profesores no dio elementos suficientes para problematizar la educación globalizante y se centra, en este caso, en la preservación de la lengua nativa y en el aprendizaje del español como segunda lengua.

\section{La relación familia-escuela-territorio: un proceso metodológico de la práctica pedagógica que se hizo insurgente}

Las casas se ven oscuras desde afuera, sus habitantes en los amplios aleros, hamacándose, conversan y ven pasar el tiempo; los niños son parte del paisaje y le imprimen al lugar un halo de confianza. Solo cuando un "blanco" o el rugir de una moto aparece, vuelven la mirada a manera de feedback unidimensional que intimida al visitante y a la vez le hace sentir la condición de otro, "el blanco", en lugar ajeno.

En el centro del resguardo se encuentra la escuela cuyos inicios se remontan a una construcción hecha a pulso por los miembros de la comunidad; al pasar el tiempo, y luego de un largo proceso, el sistema educativo Colombiano la reconoció como escuela rural. Así se volvió parte del sistema educativo nacional, lo que obligó a una asignación de recursos en maestros, procesos de formación, algo de dotación y, además, su ingreso al sistema de etnoeducación e interculturalidad, luego de una lucha nacional como pueblos originarios a lo largo del país.

Se garantizó así el derecho fundamental a la educación, pero desde una concepción colonizadora y con la pretensión de

[...] integrar al indígena al modelo de vida de la sociedad moderna, basado en el modelo liberal homogenizante e individualizante; en contraposición con los derechos étnicos-culturales y las manifestaciones de la vida comunitaria, partícipes en la cohesión del sujeto indígena. (Angarita y Campo, 2015, p. 179). 
Es por ello que al llegar el modelo sin ser cuestionado por la misma comunidad se reprodujo y la escuela por momentos parece detenida en el tiempo, no solo por sus prácticas pedagógicas, sino por las demandas comunitarias frente a los aprendizajes, que se circunscriben a escribir y hablar el español para, posteriormente, vincular a los jóvenes al mundo laboral de la región y, en muy pocos casos, continuar con sus estudios.

Por esta razón, el proceso de enseñanza-aprendizaje de los niños de los grados transición y primero se basan en tablero y tiza, guías de Escuela Nueva ${ }^{5}$ que usan muy de vez en cuando y que no son un material cercano o que se refiera a los elementos de su cultura o de su cotidianidad. En esa lógica, los niños de 4 a 6 años llegan a la escuela en diferentes momentos, con un cuaderno bajo el brazo y esperan instrucciones, pero en su condición de indígenas subvierten este "orden" y ejercen prácticas que los hacen particulares en su territorialidad, es decir, la relación escuela-familia-casa se da más allá de los tiempos y espacios signados por la escuela, pues si bien los niños llegan puntuales, salen del salón cuando lo necesitan, a beber agua, al baño, a tomar refrigerio, verse con sus padres y en muchos casos no vuelven. Así lo registra el diario de campo (18 de octubre del 2018): "[...] después los niños y niñas exhaustos de jugar se desplazaron a sus hogares a comer y beber agua, y no volvieron más por el calor tan fuerte que estaba haciendo". También, pueden faltar varios días, Ilegan a diferentes horas, cuando llueve no van, algunos no usan zapatos, no usan uniforme, las familias no siempre esperan un informe pero la escuela se empeña en entregarlo (boletín), con una concepción de infancia evolucionista que nada tiene que ver con las particularidades que plantea la etnoeducación en el sentido de la pertinencia de una educación propia no solo como derecho, sino como una necesidad de comprender el entorno sociocultural, atendiendo en este y en todos los casos a que la escuela es el otro espacio de la socialización donde se transmite la cultura.

Desde la práctica pedagógica que se desarrolla en la Universidad de Los Llanos, en la Licenciatura en Educación Infantil hubo que desaprender la idea de escuela y con ella la de práctica pedagógica. A la manera de Walsh (2013), entendimos cómo se podría enlazar lo pedagógico con lo decolonial, es decir, nuestras construcciones de maestras pasaron por desestructurar los aprendizajes pedagógicos derivados de la tradición escolástica y nos dejamos sensibilizar por la cosmovisión. Resituamos de esta manera la concepción de infancia indígena, de escuela, de familia y de comunidad e hicimos un ejercicio investigativo a partir de la cartografía social, la

5 Son guías de aprendizaje que obedecen al modelo de Escuela Nueva que se asumió en Colombia para las escuelas rurales con modalidad unitaria (un solo profesor para todos los grados en la educación primaria) o multigrado (un profesor para dos grados). Son cartillas impresas para el profesor y el estudiante, que orientan el aprendizaje a través del trabajo autónomo y colaborativo en el aula y fuera de ella. 
etnografía educativa que permitió compartir momentos donde se derrumbaron los muros de la escuela y el territorio representado en el río, el calor del sol, la pesca, el sancocho, el palo de mago, las fiestas, los juegos tradicionales, que se convirtieron en aulas alternativas y nos volvieron sujetos que aun sin compartir la misma lengua compartían la misma risa, y tanto los niños como nosotros nos anegamos en una práctica intercultural. De esta manera, y no sin esfuerzos, resituamos la idea de práctica pedagógica, y la volvimos práctica insurgente puesto que para nosotros formadores, la práctica en esta comunidad indígena nos permitió, a la manera de Larrosa (1995), "pensar de otro modo, explorar nuevos sentidos, ensayar nuevas metáforas" (p. 260). Nos habíamos traicionado, puesto que habíamos llegado en modo colonizador, con diseños de aulas alejadas y encerradas.

Por ello, el carácter interpretativo del enfoque hermenéutico nos daba elementos para reconocer una realidad instalada y desconocida para las investigadoras, donde la percepción nos permitía interpretar los fenómenos en un tiempo espacio situado en el de los sujetos, en sus propias realidades, con las familias, la comunidad, los niños, los profesores y en su propio territorio, desde sus propias prácticas. Allí, los lenguajes se cruzan, se dejan leer como símbolos y significados.

Nos ubicamos entonces en el modelo etnográfico para poder abordar la pregunta por otras prácticas que posibilitaran aprendizajes que también se constituían en lenguajes vividos y construidos con los mismos profesores, las familias y los niños desde la caza, la pesca, los alimentos, los juegos que también se volvían escritura y relatos en la lucha por una educación propia. Para este ejercicio, utilizamos varias técnicas de recolección de información, como el diario de campo, la entrevista, el juego, el caminar, el trepar el árbol, es decir, el conocimiento de la vida cotidiana con y en la comunidad. La cartografía social, las fichas de observación, fueron entonces parte de una práctica exploratoria que llevó a las investigadoras a configurar una idea de etnoeducacion en la que niños, maestros y familias se hicieron maestros y alumnos a la vez, para enseñarnos que la escuela es el territorio y que el territorio es la familia con la cual el aprendizaje es cotidiano y no enciclopédico, bancario (Freire, 2010) o lejano.

En esta lógica "pedagógica decolonial e insurgente", la etnografía educativa se cristalizó como práctica investigativa porque además nos planteó la pregunta por la formación de los maestros situados en estos territorios, donde la escuela debe transitar hacia un escenario cultural que posibilite horizontes, para comprender otras realidades, otros tiempos, otros espacios, otros sujetos y otros mundos que se habitan y habitan en horizontes aún inexplorados por nosotros mismos. La realidad se vuelve cambiante, móvil y se reconoce como comunitaria, es decir de todos y con todos, lo planeado por momentos se vuelve improbable si no habla con lo que transcurre, si no se escucha al sujeto niño. 
Todas las apuestas eran incertidumbre, como es propio de la desestructuración conceptual que requeríamos de la práctica pedagógica:

[...] empezamos a organizar los utensilios para la elaboración del sancocho $[\ldots]$ parecía que ninguna persona iba a asistir [...] después de varios minutos el docente me comenta que siguiéramos para ver lo que pasaba, él sí sabía, yo en cambio tenía miedo, tan pronto la moto empezó a moverse, las personas también empezaron a salir, los niños los adultos, nos seguían por el camino, unos a pie, otros en cicla y los demás en moto, entendí que estaban esperando a que saliéramos para que ellos también se fueran con nosotros.

Al llegar al rio, las mujeres empezaron a poicar ${ }^{6}$ el recado, organizar la olla, mientras los hombres traían el agua y la leña, después me di cuenta cómo varios hombres se dispusieron a pescar mostrándoles a algunos niños como se hacía. Después se realizó una integración con un juego, varias mujeres se quedaron sentadas y no quisieron participar mientras las más jóvenes jugaron un tiempo, durante el compartir del sancocho los niños, niñas, adultos se fueron sentando alrededor del fogón esperando su plato de comida... Al regresar me vine acompañada de varias mujeres y les pregunté cómo les había parecido, sin importar que no entendí muy bien lo que me querían decir, sabía que estaban alegres... (Diario de campo, 23 de octubre de 2018. Elaborado por la estudiante Paola Rivero).

Así las cosas, la escuela se hizo territorio y el territorio se hizo escuela. Mientras se cocinaba, se hablaba la lengua; nos vinculaban a través de los profesores con el español, pero también con la emoción que implicaba un almuerzo al igual que una fiesta, luego le dimos valor a otros lenguajes para entender que el conocimiento está inscrito en la cotidianidad y que los niños y niñas solo quieren traducir eso que viven, a una interpretación que llega a la escuela como ese otro que se quiere inscribir en un cuaderno que llega bajo un brazo.

\section{Resultados que resuenan}

El proceso de práctica pedagógica inicialmente fue concebido desde la intervención, con una noción de niño carente y desde una concepción desarrollista, que si bien reconocía a los sujetos niños indígenas que asistían a la escuela rural del resguardo como participativos, puesto que se había planteado un "proyecto de aula" que recogía previamente los intereses de los niños, su puesta en marcha en un inicio, se vio truncada porque

6 Se refiere a 'agrupar', 'recolectar'. Es una expresión propia del idioma campesino de los Llanos Orientales de Colombia; la estudiante lo utiliza para referir cómo las mujeres se encargan de recopilar los ingredientes para preparar el sancocho. Una sopa con papa, yuca, pescado y otros ingredientes, que se cocina con fuego de leña a la orilla de un río. 
estaba concebido desde las lógicas de la escolarización de la primera infancia que por tiempos ha situado la formación de los profesionales en educación infantil en lugares seguros, donde los niños se ven movidos y atraídos por propuestas didácticas que en últimas, colocan al niño en el lugar del juego o de la creación que implica la motricidad y otras áreas del desarrollo, pero que terminan siendo conducidos hacia unos intereses definidos por el maestro.

Así las cosas, los procesos de planeación se vuelven lugares seguros, prescritos que casi siempre surten efectos de avance y que permiten una secuencialidad donde implican lo que el MEN ha denominado como pilares, dimensiones, competencias. En fin, caben en formatos que facilitan más el seguimiento del paso a paso del profesor, que de las construcciones y felicidades de los niños, entendiendo por felicidad el placer de conocer lo nuevo o resignificar lo viejo. Esa era nuestra ruta, fallida por supuesto.

Ayudados de la etnografía, comenzamos a dibujar unas categorías iniciales que nos condujeron a caminar otros rumbos, inciertos, pero con nuevos zapatos, los de la pregunta por la etnoeducación, maestro indígena, niño indígena, territorio, familia. Las entrevistas con los profesores y la cercanía de algunas familias nos permitieron entrar en las casas que, al inicio, sentimos extrañas. Nos invitaron a preparar el casabe, a entender en el sancocho que el territorio no es solo físico y que es tan amplio que la escuela derriba los muros; cuando el niño corre de un lugar a otro se lo apropia, como si lo fuéramos a detener. Hicimos cartografías con las familias y nos narraron el territorio, nos mostraron dónde estaba el río, dónde no podíamos ir porque la empresa los había sacado, nos mostraron el árbol del tutú con el que luego hicimos unos objetos para jugar y en el que la mujer tiene un papel diferente al del hombre.

Las caminatas con las familias por el territorio se convirtieron en aulas, porque también aprendimos juntos que su cultura los hace sentir seguros y que a los niños los protegen narrando en su propia lengua. Los niños igualmente nos llevaron muchas veces al río, nos mojamos los pies y nos reímos con el agua. El árbol de mango muchas veces fue el sitio de encuentro, la sombra del aprendizaje, para señalarnos lo alto y lo ancho de su llanura. Muchas de las conversaciones a las que los niños nos llevaron fueron con el capitán tradicional

[...] me invitaron a pasar frente a ellos y debía colocarme una corona hecha de paja tejida a mano, y sostener en la mano una calabaza con cuernos de venado el cual representaba el poder y la armonía de convivir y compartir con todos, antes de iniciar el ritual me dijeron que debía quitarme los zapatos, porque estar descalza muestra respeto y conexión con la madre tierra, en este sentido durante la danza debía estar en un solo lugar agitando un palo largo de colores y con forma de bastón y 
esperar que ellos giraran alrededor, imitando varios sonidos de animales feroces, así se realizó el ritual por varios minutos las madres disfrutaron del evento. (Diario de campo, 17 de septiembre del 2018).

En este trasegar, resignificamos las categorías, y los niños indígenas nos enseñaron su mundo, distante para nosotros pero suyo. En el desplazamiento, y el andar ágil, veloz, hicimos lenguajes comunes para aprender algunas letras del español; ya no sabíamos si era importante, pero comprendimos que se precisaba necesario. El palo de mango se hizo aula, el chigüiro, ${ }^{7}$ su mascota, nos acompañó a la escuela muchas veces; la Iluvia nos impidió llegar a tiempo, pero nos abrigó en su sonido y nos mojó el alma para sentir que estamos vivos. Esa fue la etnoeducación, una vida propia que busca ser leída y no encerrada.

\section{Se concluye... tal vez, apenas comienza. Una escuela en la comunidad Piapoco-Achagua que abre sus posibilidades hacia el territorio}

Esa escuela que está en el centro del resguardo convoca, es vinculante y es un referente de que allí está la infancia, el profesor es respetado y en el día a día los profesores esperan a los niños que llegan. Aunque se instaura y se funda desde un criterio hegemónico, responde a la formación igualmente occidentalizada en la que fueron formados los mismos docentes. Es derivado de aquello que Álvarez (1995) denominó el proyecto hegemónico europeizante que consolida los Estados-Nación, cuyo fundamento es el cristianismo occidental como doctrina higienizante y de moralización en el nombre del desarrollo y la civilización. La escuela allí también se inaugura con un sentido alfabetizante hacia el español, que va cambiando igual que en Colombia, hacia la función de minorizar la ignorancia y la pobreza, que se consideraban la una como causa de la otra. Es parte de la construcción histórica de la escuela en nuestro país, pero que se reproduce como modelo que se crea para esperar o justificar la acción benéfica del Gobierno, en una idea, por qué no, civilizatoria. En este sentido, algunos miembros de la comunidad que salen al casco urbano se sitúan en una posición minoritaria, donde son mirados por los citadinos con conmiseración o, en algunos casos, en posición de mendicidad.

Desde esta perspectiva, la escuela requiere emanciparse, volverse sujeto no solo para proteger, sino para proveer herramientas de filiación social y cultural que se integran a las múltiples situaciones en las cuales

7 También Ilamado capibara, carpincho. Es un animal de cuerpo cilíndrico, inofensivo, con pelaje en todo su cuerpo. Tiene una trompa roma o aplanada, es roedor y se deja consentir. Se encentran muchos en las zonas selváticas y llanas. 
es receptora de cuidados y protección, pero al mismo tiempo portadora de pensamiento, valores, interacciones y decisiones. En este proceso vale la pena pensar cómo configurar una escuela que teja múltiples relaciones que obliguen a los sujetos a desestructurar, si se quiere, la misma noción de escuela, familia, comunidad para construir sujetos capaces de decidir, asumir, enfrentarse al mundo de manera autónoma, pero con los otros, con ese mismo sentido comunitario que invita el territorio.

Cabe pensar que la etnoeducación, por lo menos en la formación de maestros, debe volver a la magia que menciona Kusch (1976), "la de la vida diaria", la que nos enfrenta a nosotros mismos, a nuestros deseos, a nuestras pasiones que no se dan en el etéreo, sino con relación al lugar que habitamos. El autor pregunta: " $i$ Y esto no es acaso un poco indio? Solo que el indio o campesino sabe qué hacer con el miedo" (p. 29). Los niños con los que compartimos en el proceso de la práctica nos lo mostraron, cuando los profesores nos llevaban en moto camino al resguardo, también: detectaban una culebra venenosa y se bajaban a quitarle la cabeza, se trepaban en el palo de mango, cruzaban el río con destreza, dominaban el calor, prendían el fuego para el fogón con agilidad, recorrían grandes distancias corriendo hábilmente y dejándonos en el camino. Esa era nuestra práctica, la del reconocimiento y dominio de un mundo que no es el nuestro de grandes edificios y arquitecturas que invitan a estar estático y no afuera, en movimiento como es la invitación de los niños del resguardo. Es posible hacer allí escuela, en el afuera, con la familia que acompaña y que construye también saber fuera del cuaderno y el lápiz.

Cuando el niño, independientemente si es o no de una etnia, se siente reconocido en su saber y participa de las acciones de aprendizaje, se va asumiendo como agente de cambio y va transformando su entorno resolviendo problemas, dando sus opiniones. De lo contrario, como dice Bustelo (2007), cuando hay acciones de dominación de manera permanente, los agentes que detentan el poder se legitiman con un discurso distorsionado que otorga legitimidad a los participantes dóciles y al mismo tiempo, consiguen dejar de ser reconocidos como lo que son: esto es, poder y dominación.

En estas relaciones con la escuela tradicional, los niños de la primera infancia van de manera intermitente a la escuela, hablan su lengua con los profesores y son el referente a quienes acatan, pero cuyo interés parece ser, no institucionalizarlos, sino establecer una relación de acercamiento y socialización de la infancia en aras de compartir las costumbres y consignar en el cuaderno unos intereses de acercamiento al español, pero que se traduce en una cotidianidad escolar de planas y sin conexión con el territorio. Solo que sus prácticas pedagógicas vuelven de manera permanente a esa relación heredada maestro-alumno. 
Las relaciones e interacciones son fundamentales para la subjetividad, porque el niño y el joven interactúan con los demás y los demás con ellos. Estas situaciones conllevan a que el sujeto vaya asumiendo responsabilidades sociales y decidiendo frente a la existencia misma, a preguntarse por su papel en el mundo, por ejemplo, a decidir frente a su identidad, que no puede ser ignorada ni por la escuela, ni por la familia indígena, y menos aún por el Estado y por la Universidad, que forma profesores para los territorios. Es decir, está contribuyendo a la configuración de sujetos dentro de una cultura presente y futura, porque no siempre se es niño y adolescente, sino que se pasa a una vida adulta en la cual se debe tener capacidad de responder frente a situaciones complejas, incluso de peligro. Esto solo lo aprende en compañía del adulto, del sabedor, del profesor que decidió ser maestro en su comunidad.

Es necesario, por otro lado, que los niños y adolescentes indígenas no sean sometidos a las condiciones sociales, sino que tengan la posibilidad de hacer en el mundo, de relacionarse con los otros, dejando de ser la víctima para pasar a tener la potestad de ser sujeto, no solo de derechos, sino de su proceso de formación social frente a los otros, en la capacidad de entender situaciones sociales que le afectan directamente. Es decir, en qué momento la subjetividad del niño como integrante de una comunidad indígena tiene la capacidad no solo de decidir frente al mercado occidental, sino ante situaciones reales y problemáticas.

La infancia y la adolescencia como nacimiento y comienzo de la vida implican que en ese campo se "juegue" el gran partido cuyo resultado tendrá un impacto directo sobre una política emancipatoria. Por lo pronto, el capitalismo conoce muy bien que allí es donde se "incuba" y se reproduce su poder y por ello realiza ingentes esfuerzos para controlar la construcción de la naciente subjetividad. (Bustelo, 2007, p.182)

Los niños de la primera infancia indígena no son la excepción. Antes bien, la escuela fundada en estas mismas estructuras pone en riesgo la comunidad misma y con ella los procesos de paz que se siembran en su interior y en la familia que resguarda la cultura y el territorio que habitan. Así pues, la etnoeducación pasa por aquello que llama Larrosa (1995): "prácticas centradas en la adquisición", donde "no se enseña explícitamente nada. Sin embargo se aprenden muchas cosas". Así las cosas, la etnoeducación o la educación propia debe ser una propuesta de formación política de los maestros, y las universidades deben preguntarse por el reconocimiento cultural, social y político de las comunidades indígenas, pero en relación con su territorio y con propuestas didácticas que nacen de la cotidianidad y del saber situado, de la mano de las familias y con una escuela que dialogue, sin barreras. 


\section{Referencias}

Álvarez A. (1995). ... y la escuela se hizo necesaria. Editorial Magisterio.

Angarita-Ossa, J. J. y Campo-Ángel, J. N. (2015). La educación indígena en proceso: Sujeto, escuela y autonomía en el Cauca, Colombia. Entramado, 11(1), 176-185. http://dx.doi.org/10.18041/entramado.2015v11n1.21129

Ardila, R. A. (2015). Negocios con empresas extractivas, estudio de caso en Colombia: de cómo las comunidades pueden empoderarse para afrontar exitosamente negociaciones frente a las empresas extractivas. Academia Española.

Bustelo, E. S. (2007). El recreo de la infancia: Argumentos para otro comienzo. Siglo xxı Argentina.

Castillo, E. (2008). Etnoeducación y políticas educativas en Colombia: La fragmentación de los derechos. Educación y Pedagogía, 20(52), 15-26.

Kusch, R. (1976). Geocultura del hombre Americano. Fernando García Cambeiro.

Larrosa, J. (Ed.) (1995). Escuela, poder y subjetivación. Editorial La Piqueta.

Rojas, T. (2019). Una mirada a los procesos en torno a la educación con los pueblos indígenas en Colombia. Voces y Silencios: Revista Latinoamericana de Educación, 10(1), 9-34.

Santos, B. de S. (2010). Descolonizar el saber, reinventar el poder. Ediciones Trilce.

Semper, F. (2006). Los derechos de los pueblos indígenas de Colombia en la jurisprudencia de la Corte Constitucional. Biblioteca Jurídica Virtual del Instituto de Investigaciones Jurídicas de la UNAM. Www. jurídicas.unam.mx

Walsh, C. (2013). Pedagogías decoloniales. Prácticas insurgentes de resistir, (re)existir, (re)vivir (tomo 1). Ediciones Abya Yala. 